\title{
Effect of kind and method of fungicidal treatment of bean seed on infections by the VA-mycorrhizal fungus Glomus macrocarpum and by the pathogenic fungus $F$ usarium solani
}

\author{
I. Fungal and plant parameters
}

\author{
E.J. GONÇALVES, J.J. MUCHOVEJ and ROSA M.C. MUCHOVEJ' \\ Departamento de Fitopatologia. 'Departamento de Biologia Geral. Universidade Federal de Viçosa, \\ 36570, Viçosa, MG, Brazil
}

Received 18 April 1990. Revised September 1990

Key words: benomyl, captan, dichloromethane, ethanol, fresh root weight, top dry weight, fungicidal seed treatment, Fusarium solani, Glomus macrocarpum, Phaseolus vulgaris

\begin{abstract}
To test the effect of seed treatment with fungicides on the development of mycorrhizal fungi, bean seeds were treated with fungicide dry or vehicled in the organic solvents, ethanol or dichloromethane and then planted in soil inoculated with the mycorrhizal fungus Glomus macrocarpum and/or the plant pathogenic fungus Fusarium solani. Measurements were made at 4 day intervals, to assess the presence of mycorrhizae or disease in the roots as well as top dry weight, root fresh weight and root length. Fungicidal seed treatment did not affect the initial occurrence of mycorrhizae, number of spores of G. macrocarpum in the soil or root length. Fresh weights of roots and dry weights of tops were greater in the presence of the mycorrhizal fungus. The onslaught of symptoms by $F$. solani was significantly retarded by treatment with fungicides plus mycorrhizal fungi or fungicides plus organic solvents.
\end{abstract}

\section{Introduction}

Vesicular-arbuscular (VA) mycorrhizal fungi are important in the ecology of many agronomically important crops (Harley, 1989; Mosse et al., 1981) and the association is beneficial to crop plants through increased absorption of nutrients and water as well as protection against pathogens (Hayman, 1983). However, these VA fungi are theoretically exposed to any pesticide which is applied to the soil or to seeds which are then planted. This study tested the effect of fungicide treatment of bean seeds on subsequent development of VA-mycorrhizas by the mycorrhizal fungus Glomus macrocarpum and of root rot by the pathogenic fungus Fusarium solani, in soil containing either one or both of those fungi.

\section{Materials and methods}

Chopped up mycorrhizal and non-mycorrhizal roots, spores and substrate from pot cultures with forage sorghum was used as inoculum. The spore count in the final inoculum was 81.3 spores per $g$ soil. This inoculum was mixed uniformly into a soil : sand mixture to provide a final spore count of 200 spores per $100 \mathrm{~g}$ soil. The soil used for the mixture was from the A horizon of a Typic Haplorthox clayey, kaolinitic isothermic soil with an original $\mathrm{pH}\left(\mathrm{H}_{2} \mathrm{O} 1: 2.5\right)$ of 4.4 which was amended with $\mathrm{CaCO}_{3}$ and nutrients. The chemical characteristics of the final soil: sand mixture were $\mathrm{pH} \quad\left(\mathrm{H}_{2} \mathrm{O} 1: 2.5\right)$ 5.4; $15.7 \mu \mathrm{g} \mathrm{g}^{-1} \mathrm{P} ; 12.1 \mu \mathrm{g} \mathrm{g}^{-1} \mathrm{~K} ; 0,1.8$ and $0.6 \mathrm{eq}$ $\mathrm{mg} / 100 \mathrm{~cm}^{3}$ of $\mathrm{Al}^{+3}, \mathrm{Ca}^{+2}$ and $\mathrm{Mg}^{+2}$, respective- 
ly. This mixture, from here on referred to as soil, was treated with methyl bromide $(40 \mathrm{~mL}$ per $\mathrm{T})$ to eliminate native fungi and seeds, before incorporation of the respective inoculums.

Inoculum of $F$. solani was prepared by incubating cultures of the fungus on potato dextrose agar (Tuite, 1969) containing sucrose reduced to $10 \mathrm{~g} \mathrm{l}^{-1}$, in petri dishes. After 12 days of growth, the surface of the colony was flooded with sterile water and spores loosened with a soft bristle brush. This suspension was then collected and the number of spores per $\mathrm{ml}$ was determined using a haemacytometer. The spore count of the total number of spores (microconidia, macroconidia and chlamydospores) was adjusted to $10^{6}$ chlamydospores $\mathrm{mL}^{-1}$. The inoculum was mixed uniformly into the soil to provide a final spore count of $2 \times 10^{5}$ spores $100 \mathrm{~g}^{-1}$ soil.

Seeds of bean (Phaseolus vulgaris $\mathrm{cv}$. Carioca) were either non-treated or treated with the fungicides benomyl [methyl - 1 - (butylcabamoyl)benzimidazol - $2 \mathrm{yl}$ - carbamate] or captan $[3 \mathrm{a}, 4,7$, $7 \mathrm{a}$ - tetrahydro - N - (trichloromethanesulphenyl)phthalimide] as dry treatments or vehicled in the organic solvents dichloromethane (DCM) or ethanol for $30 \mathrm{~min}$ (Dhingra and Muchovej, 1980; Muchovej, 1987; Muchovej and Dhingra, 1980). Control treatments consisted of untreated seeds or seeds soaked in organic solvent alone.

The soil was placed in black, plastic bags which contained $1.5 \mathrm{~kg}$ for the evaluations through 16 days, $3 \mathrm{~kg}$ for the evaluations through 28 days and $4.5 \mathrm{~kg}$ for the evaluations through 40 days. The bags had three 6-mm dia holes punched in the base to allow for drainage. One seed was planted per bag and these were kept in the greenhouse where temperatures varied between 22 and $30^{\circ} \mathrm{C}$. A total of 1440 bags were planted and these were randomly distributed. Each bag was considered a repetition.

At 4 day intervals, beginning after planting, the tops of 4 plants per each soil : fungicide : solvent combination were harvested, and the soilroot system collected. The plant tops were placed in paper bags in a forced air oven at $70^{\circ} \mathrm{C}$ until constant weights were obtained. Samples of soil were collected and assayed for spores. The roots were carefully separated intact from the soil, washed, patted dry between paper towels, and fresh weights and lengths determined. The roots were then visually inspected for colonization by Fusarium solani which produces reddish symptoms (Burke and Miller, 1983). The entire root system was then stained (Phillips and Hayman, 1970) and checked for colonization by G. Macrocarpum using a stereomicroscope. These results are presented separately (Muchovej et al. 1991). Harvests continued for 10 sampling periods, when approximately $50 \%$ of the plants inoculated with the mycorrhizal fungus had begun to flower. All treatments were done in 4 replicates. The differences between the slopes and intercepts of the linear regressions of the values obtained were analyzed statistically for their significance.

\section{Results}

Mycorrhizae and spores of $G$. macrocarpum were found only in treatments which had been inoculated with the mycorrhizal fungus. In all cases and in all replications, mycorrhizae were first observed on the fourth collection time (Day 16). There was no significant effect of any treatment on the number of mycorrhizal spores present at any time during the experiment.

There were only minor variations in the length of the roots as a result of any treatment (Fig. 1). There was a constant increase in the root length throughout the experiment and these increases, as evidenced by the slopes of the calculated regressions did not differ biologically between treatments.

Root fresh weights (Fig. 2) did not vary considerably as a result of treatment but, root production of plants inoculated with mycorrhizal fungi was superior to that of those not inoculated. Interestingly, the seeds that were treated with fungicides in ethanol or just the solvent ethanol, provided plants with the greatest root fresh weights. The rate of increase of root fresh weight was greater in most cases when captan was the fungicide, although these increases were not always significantly superior to the other fungicides or solvents alone.

Dry weights of the tops of the bean plants were greater when the seeds were planted in soil which contained the mycorrhizal fungus (Fig. 3). Within each solvent or within the dry fungicide 


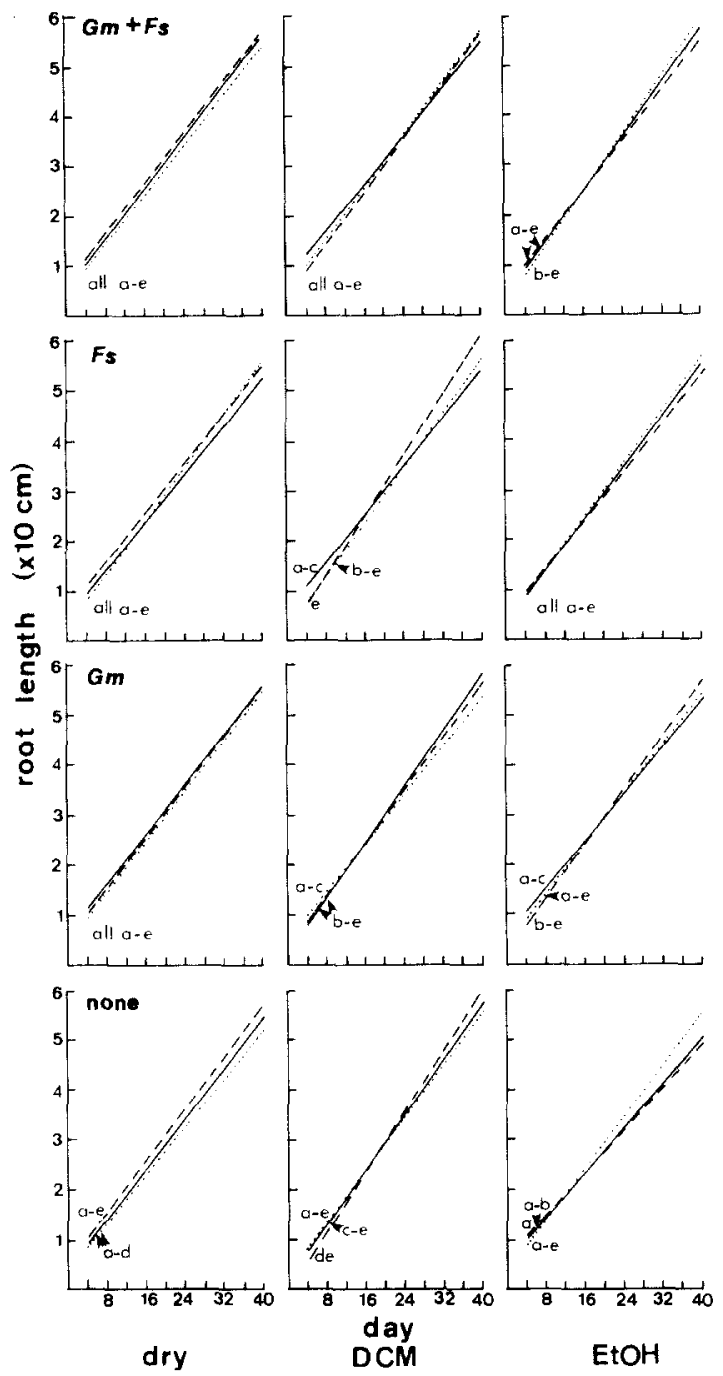

Fig. I. Length of roots of bean plants grown from seeds not treated (solid line) or treated with captan (dotted line) or benomyl (dashed line), dry, in ethanol or in dichloromethane and cultivated in soil not inoculated or inoculated with Glomus macrocarpum, Fusarium solani or both. Slopes of lines marked with the same letter did not differ at the $p=0.05$ level.

treatment, the plant top weight was greatest when both the mycorrhizal fungus and the pathogen were added. By the same token, the dry weights of plants which were grown in soil containing $F$. solani were lower than those grown in unamended soil.

The initial incidence of symptoms of $F$. solani varied considerably depending on fungicide: mycorrhizae: solvent treatment (Fig. 4). With

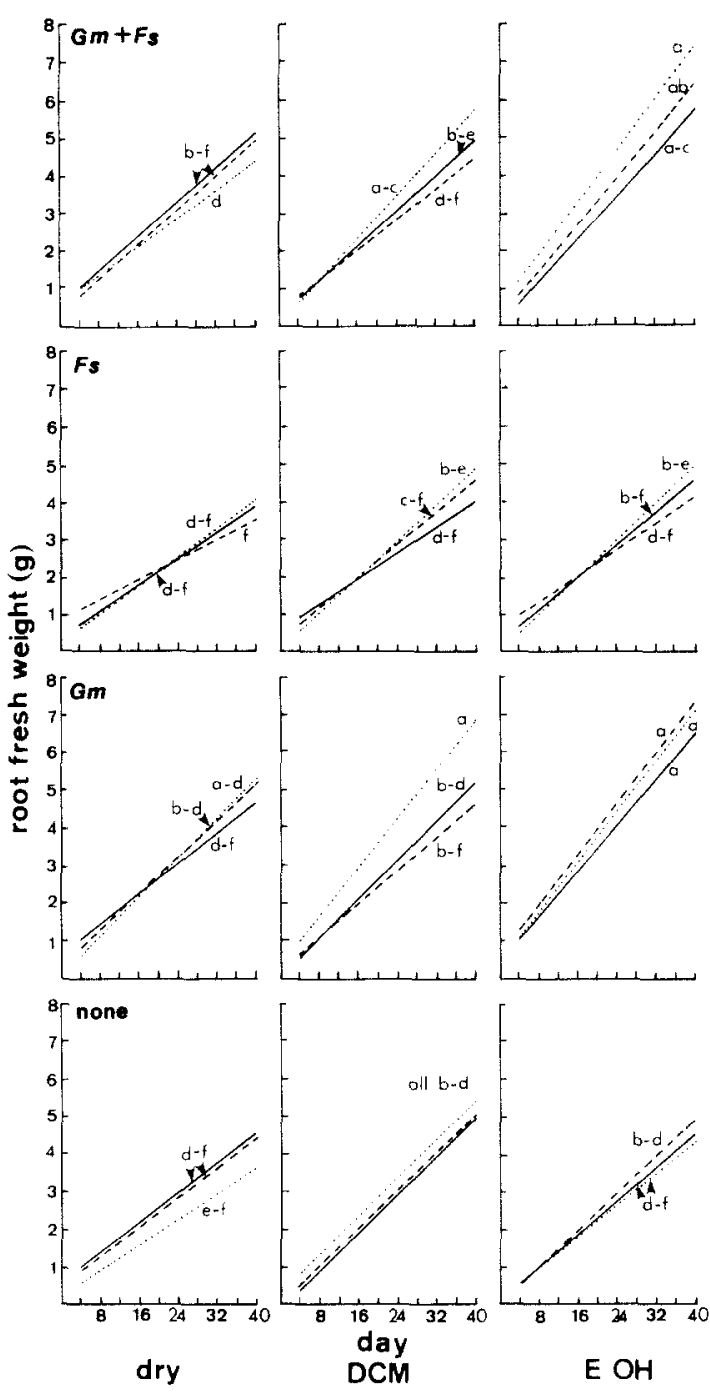

Fig. 2. Fresh weights of roots of bean plants grown from seeds not treated (solid line) or treated with captan (dotted line) or benomyl (dashed line), dry, in ethanol or in dichloromethane and cultivated in soil not inoculated or inoculated with Glomus macrocarpum. Fusarium solani or both. Slopes of lines marked with the same letter did not differ at the $p=0.05$ level.

DCM, there was no real variation between fungicide: mycorrhizae treatments, while with ethanol as a solvent, the fungicides afforded some protection although the association with the mycorrhizal fungus afforded more. With dry fungicide, there was no significant effect of the presence of fungicide per se, while the presence of $G$. macrocarpum, extended, significantly, the time at which disease was first observed. 


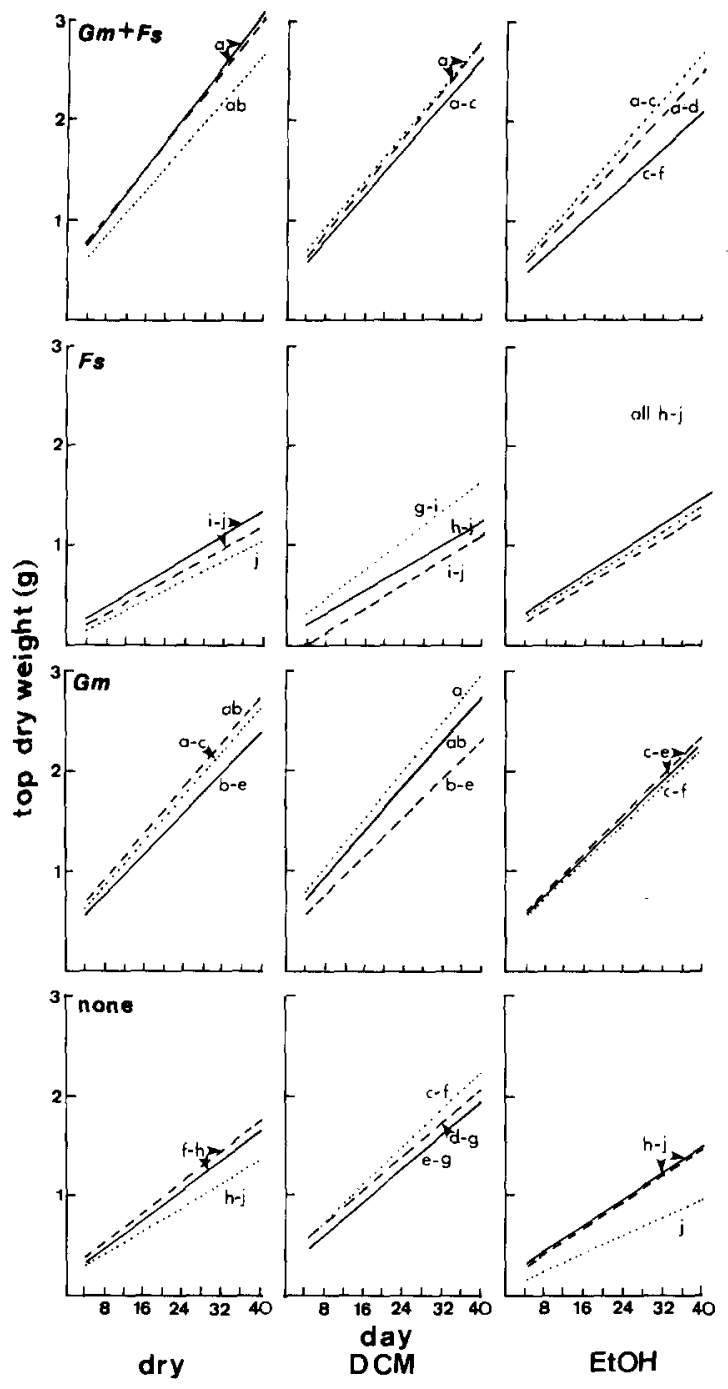

Fig. 3. Dry weights of tops of bean plants grown from seeds not treated (solid line) or treated with captan (dotted line) or benomyl (dashed line), dry, in ethanol or in dichloromethane and cultivated in soil not inoculated or inoculated with Glomus macrocarpum, Fusarium solani or both. Slopes of lines marked with the same letter did not differ at the $p=0.05$ level.

\section{Discussion}

Based on these observations, there was no real effect as a result of any treatment on the initial occurrence of mycorrhizae or the quantity of spores found in the soil, and only minor variations in root length. Fresh root weights and top

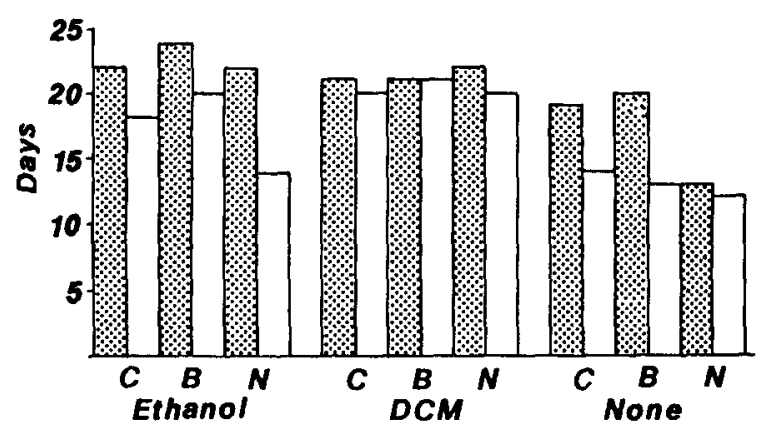

Fig. 4. Average date of first observation of symptoms of Fusarium solani. Solid bars represent plants grown in soil containing inoculum of $G$. macrocarpum. C- seeds treated with captan, B- seeds treated with benomyl, $\mathrm{N}$ - no fungicide treatment of seeds, ethanol $=$ fungicide applied dissolved in ethanol, DCM- fungicide applied dissolved in dichloromethane, None- fungicide applied dry.

dry weights were superior when mycorrhizae were present. Fresh root weights were increased by seed treatment in ethanol while top dry weights were increased by seed treatment in dichloromethane. In order for mycorrhizal infection to diminish the onset of disease, seed treatment with either fungicide or organic solvent was necessary.

Much has been written on the effect of seed treatment with fungicides on mycorrhizal fungi. Many of these reports include either no-effect or slight deleterious effects (Trappe et al., 1984). Benzimidizole components of fungicides have been reported to have antifungal activity that is particularly suppressive of Zygomycetous fungi such as the Endogonaceous mycorrhizal fungi (Rhodes and Larsen, 1981; Sutton and Sheppard, 1976; Trappe et al., 1984). Based on this benomyl has been recommended for the control of VA mycorrhizal infections from fungi which occur naturally in the soil (Fitter and Nichols, 1988). The control was dependent on renewal of the fungicide and when the fungicide was withheld, infection would occur within 10-20 days (Fitter and Nichols, 1988). Initial reductions in infection caused by the lower dosages $2.5 \mu \mathrm{g}$ benomyl/g of soil, did not differ from reductions caused by dosages two magnitudes greater (Bailey and Safir, 1978). 
In our study, seed treatment with benomyl did not suppress the initial occurrence of mycorrhizal infections. While the initial occurrence was at 16 days, and this is within the 10-20 day limit established by Fitter and Nichols (1988), no treatment afforded colonization at earlier dates. Since no further benomyl was applied, no further reductions occurred. Interestingly, seed treated with benomyl produced plants with greater top dry weights.

Captan, however, does not appear to have as great an effect on the occurrence of mycorrhizae as other fungicides, although reductions have been reported (Neshein and Linn, 1959; Sutton and Sheppard, 1976). In our study, captan afforded greater root development as measured by fresh weight and root length. These parameters are not always looked at and as our study shows, are not always correlated with the greatest top dry weight produced.

Organic solvents have been recommended as vehicles for fungicidal seed treatments to prevent the deleterious effects of seed coat slippage and initiation of germination which may occur when fungicide is added moist (Dhingra and Muchovej, 1980; Muchovej and Dhingra, 1980). With respect to the number of mycorrhizal spores, first occurrence of mycorrhizae or root length, the organic solvents DCM and ethanol did not show any beneficial or deleterious effects. However, root fresh weights and top dry weights were increased by seed treatments with organic solvents. The most inspiring results were with respect to disease development. Initial symptoms of Fusarium were delayed considerably when the fungicide was vehicled in either solvent, and this delay was greater when the mycorrhizal fungus was present.

Based on the results of this study, seed treatment with either benomyl or captan, not only did not reduce mycorrhizal occurrence, but also helped in the reduction of disease from soil-borne $F$. solani.

While seed treatment with organic solvents may be considered ecologically risky, equipment has been developed (Dhingra and Muchovej, 1982) which allows for treatment of seeds, and total recovery of the solvent without pollution.

\section{Acknowledgements}

This research was supported in part by the Conselho Nacional de Desenvolvimento Cientifico e Tecnologico $\left(\mathrm{CNP}_{q}\right)$.

\section{References}

Bailey J E and Safir G R 1978 Effect of benomyl on soybean endomycorrhizae. Phytopathology 68, 1810-1812.

Burke D W and Miller D E 1983 Control of Fusarium root rot with resistant beans and cultural management. Plant Disease 67, 1312-1317.

Daniels B A and Skipper H D 1982 Methods for the recovery and quantitative estimation of propagules from soil. In Methods and Principles of Mycorrhizal Research. Ed. N C Schenck pp 29-35. APS, St. Paul, MN.

Dhingra O D and Muchovej J J 1980 Dichloromethane, trichloromethane and carbontetrachloride as solvents for bean seed treatment with systemic fungicides. Seed Sci. Technol. 8, 77-83.

Dhingra O D and Muchovej J J 1982 Organic solvent seed treater. Seed Sci. Technol. 10, 105-108.

Fitter A H and Nichols R 1988 The use of benomyl to control infection by vesicular-arbuscular mycorrhizal fungi. New Phytol. 110, 201-206.

Harley J L 1989 The significance of mycorrhiza. Mycol. Res. 92, 129-139.

Hayman D S 1983 The physiology of vesicular-arbuscular endomycorrhizal symbiosis. Can. J. Bot. 61, 944-963.

Mosse B, Stribley D P and LeTacon F 1981 Ecology of mycorrhizae and mycorrhizal fungi. Adv. Microb. Ecol. 5, $137-210$.

Muchovej J J 1987 Automotive ethanol for treatment of soybean seeds with fungicides. Seed Sci. Technol. 15 , 265-269.

Muchovej J J and Dhingra O D 1980 Acetone, benzene and ethanol for treating Phaseolus seed in the dry state with systemic fungicides. Seed Sci. Technol. 8, 351-356.

Muchovej J J, Muchovej R M C and Gonçalves E J 1991 Effect of kind and method of fungicidal treatment of bean seed on infections by the VA-mycorrhizal fungus Glomus macrocarpum and by the pathogenic fungus Fusarium solani. II. Temporal-spatial relationships. Plant and Soil 132 , $47-51$.

Nesheim O N and Linn M B 1959 Deleterious effects of certain fungitoxicants on the formation of mycorrhizae on corn by Endogone fasciculata and on corn root development. Phytopathology 59, 297-300.

Phillips $J$ M and Hayman D S 1970 Improved procedures for clearing roots and staining parasitic infection. Trans, $\mathrm{Br}$. Mycol. Soc. 55, 158-161. 


\section{Bean with VAM/Fusarium/fungicide}

Rhodes L H and Larsen P O 1981 Effects of fungicides on mycorrhizal development of creeping bentgrass. Plant Disease $65,145-147$.

Sutton J C and Sheppard B R 1976 Aggregation of sand-dune soil by endomycorrhizal fungi. Can. J. Bot. 54, 326-333.
Trappe J M, Molina R and Castellano M 1984 Reactions of mycorrhizal fungi and mycorrhiza formation to pesticides. Annu. Rev. Phytopathol. 22, 331-359.

Tuite J 1969 Plant Pathological Methods, Fungi and Bacteria, Burgess, MN. 